\section{Drug discovery for neglected diseases}

In recent years, public, private and philanthropic organizations worldwide have started to work together to discover and develop new medicines to treat neglected diseases. This month, we feature two people involved in these public-private partnerships.

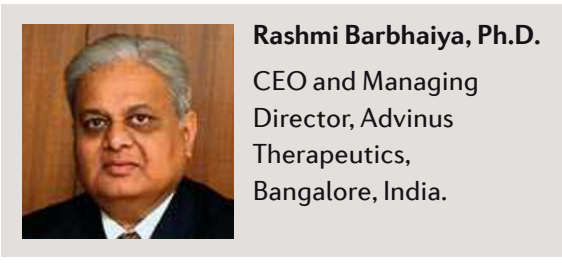

Traditionally, pharmaceutical companies in India are associated with the production of generic drugs. However, when Rashmi Barbhaiya co-founded Advinus it was with the aim of establishing the first company in India capable of doing R\&D on high-risk novel targets, including those for neglected diseases. Barbhaiya thinks that India is one of the best places to tackle such diseases. "It is one of the few countries in the world that has not only the disease burden, but also the capability to research and develop new therapies," he says.

Barbhaiya has created awareness about India in general, and Advinus in particular, for conducting RED for neglected diseases "primarily through invited speeches at international forums focusing on global health and one-on-one contacts," he explains. The success of this strategy has most recently been exemplified by Advinus's

Tim Wells, Ph.D.
Chief Scientific Officer,
Medicines for Malaria
Venture, Geneva,
Switzerland.

Officially launched in 1999, the Medicines for Malaria Venture (MMV) was one of the first public-private partnerships established to develop effective and affordable antimalarial drugs. "We have a great portfolio of projects from early screening through to three new therapies in late Phase III and to registration," says Tim Wells, Chief Scientific Officer of the MMV. "All the projects are partnered; with academic groups, contract research organizations, as well as mainstream pharmaceutical and biotech companies."

Before the MMV, Wells was Head of Research at Serono, a Swiss biotech company based in Geneva. His interest in neglected diseases was sparked at Serono when he helped set up a project with the World Health Organization's Tropical Disease Research group. “We were looking at collaboration with Genzyme and the Medicines for Malaria Venture to accelerate discovery of novel therapies for malaria.

Now, Barbhaiya's aim is for Advinus to not only help tackle neglected diseases, but also to help companies in the US and Europe discover and develop new medicines by exploring different models of innovation in India beyond the well-established opportunities for costeffectiveness. Convincing senior management of companies in the developed world to do this is, nevertheless, a significant hurdle as "India's lack of track record makes it difficult to convince sceptics," says Barbhaiya.

To this challenge, he brings more than 25 years of experience in pharmaceutical R\&D, which began at Bristol-Myers Squibb in 1980 following a chance encounter when he was a Ph.D. student in clinical pharmacology at St Bartholomew's Hospital Medical College, University of London, UK. "One of the pioneers in our field was visiting London when I was finishing my doctoral degree. He offered me a position with him in the USA after he heard my seminar and the rest is history," he says.

Over 21 years, driven by "a deep desire to succeed, commitment, passion, dependability whether any of our targets had homologues in parasites that might lead to new drugs." When Serono was sold to Merck KGaA in 2007, Wells thought it was a good time to look for something different. He says: "Part of the attraction of MMV was the desire to do more for neglected disease. It's a great organization to work for, as they have the track record and resources to make things happen. Plus, it's not every day you get the chance to join an organization with such a strong portfolio." Currently, the MMV has over 50 projects and is spending US $\$ 50$ million on science and medicine alone this year.

The MMV has also enabled Wells to "get back to the science." Since 1987, when he completed his $\mathrm{Ph}$.D. in protein engineering with Alan Fersht at Imperial College of Science and Technology, London, UK, Wells has been driven by a mixture of scientific curiosity and the desire to make a real impact on health. However, it is his experience in industry - that began at SmithKline and French after his doctorate - that repeatedly demonstrated the need for good collaborations. "Being able to spot the right partnerships and get people working together is crucial," he says.

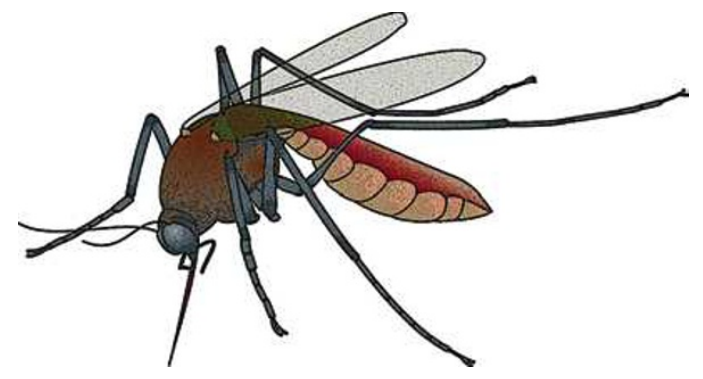

and ability to dream with eyes open,"

Barbhaiya built up his extensive experience in pharmaceutical R\&D at Bristol-Myers Squibb. As Vice President in the Pharmaceutical Research Institute he played a key role in introducing the concept of "developability" as a major criterion for lead candidate optimization, resulting in reduced timelines between discovery and development.

In 2002, he returned to India as President of R\&D at Ranbaxy, leading a team of over 900 professionals, where he experienced "young talent that is passionate and hungry to prove that India has abilities to become one of the major global pharma RED players." Barbhaiya wanted to provide opportunities for Indian scientists "to learn the science of drug discovery, art of drug development and to create a new pharma R\&D culture," and this led him to co-found Advinus.

By doing this, Barbhaiya also fulfilled his dream of becoming an entrepreneur, both creating and running his own pharma RED organization. "Above all," he concludes, "we have created the infrastructure in India that can and will put new drugs on the market, to serve unmet clinical needs with speed, efficiency and cost-effectiveness."
Wells derives particular pleasure in setting up collaborations in the not-for-profit world: "At MMV we have some amazing partnerships, and are working with very talented and highly motivated people." The collaborations with industry also present Wells with a significant challenge - reminding those in public health that industry is part of the solution. "Our pharmaceutical partners are extremely dedicated scientists and physicians who give up a lot of their time (usually their own free time) to make a difference in malaria therapy," he explains.

For those considering participating in public-private partnerships for neglected diseases Wells offers some advice: "It's almost a cliché - but success in drug discovery comes from successful teams, overlaid with a thick dose of continually questioning anything you don't understand, and being prepared to learn new things all the time."

WEB SITE

Career snapshots: http://www.nature.com/naturejobs/ magazine/career snaps.html 